\title{
Deconstructing difference and inclusion in educational research: reflections on the international journal of qualitative studies in education special edition on difference
}

\author{
M. Nickie Commer
}

\begin{abstract}
Disabled and disability studies scholars and activists have challenged and are challenging the bio- and necro-politics of disability subjectivity through scholarship, art, activism, and online engagement. As this edition articulates, difference takes many forms, is intersectional, and is often characterized and codified by and through educational research. Acknowledging that difference is socially constructed poses challenges to the ablenationalism that undergirds not only complex systems of schooling, but the educational research on which these systems rest.
\end{abstract}

Keywords: Disabled epistemologies, disability studies in education, educational research, critical disability studies

\section{Author information}

M. Nickie Coomer is a Ph.D. Candidate at Indiana University-Purdue University (Indianapolis) in the Urban Education Studies doctoral program. Her research is in the social and cultural processes in schools that construct and maintain disability in special education.

This is the author's manuscript of the work published in final form as:

Coomer, M. N. (2019). Deconstructing difference and inclusion in educational research: Reflections on the international journal of qualitative studies in education special edition on difference. International Journal of Qualitative Studies in Education, 32(3), 341-345.

https://doi.org/10.1080/09518398.2019.1578907 


\section{Deconstructing difference and inclusion in educational research: reflections on the international journal of qualitative studies in education special edition on difference}

Educational research plays a specific role in developing and sustaining notions of normative participation in schools and society. In relation to disability, some special education researchers purport that difference is a naturally occurring statistical variation of human diversity (e.g. Kauffman, Lloy, Baker, \& Reidel, 1995; Kauffman \& Badar, 2013; Kauffman \& Landrum, 2018). The assumption that statistical variance can adequately describe human difference grounds itself in the belief that difference among people is randomly distributed along a bell curve, and that there is, in fact, a normal (Dudley-Maring \& Gurn, 2010). Assuming that difference in human existence exists as an adherence to a randomly distributed variance of characteristics, however, neglects the relational, interdependent nature of human interaction and development (Dudley-Marling \& Gurn, 2010). Accordingly, any discussion of difference, especially pertaining to educational research, has to attend to the ways in which difference is measured along a perceived, constructed, or altogether invented (Gallagher, 2010) normal. Discussions of how difference manifests through race, ethnicity, gender, sexuality, religion, class, and other markers of non-White, non-cisgender, non-hetero existence subtly (or blatantly) implicates a measurement of the degree to which one is able to engage or perform a particular normalcy. The operative words in this measurement of difference are 'able to.' In this case, then, any inquiry into difference automatically requires an acknowledgement of the role of ability and dis/ability that is present in the process of othering against a normalized existence rooted in colonial settler Whiteness.

What it means to live with difference in 2018 in the global world has very material, economic, and corporeal consequences. A global trend toward societal normalizing rooted in eugenicist 
declarations about entire groups of people- categorized by race, class, ability, religion, gender, sexuality, and citizenship status- means that difference can make a person a target for not only personal and individualized aggressions, but political and economic policy that disenfranchizes those who are different from participating in a society. This is a matter of global necropolitics and ablenationalism: decisions around who lives and who dies that begin with the question of who is worthy of participating in society, and who must be the passive subjects of others' participation (Synder \& Mitchell, 2010), based on perceived and constructed difference.

What social participation looks like at a systems level by those who are deemed capable and worthy of participatory status is epitomized in schooling practices for students with dis/abilities. Special education initiatives focused on inclusion ask how students can be taught to or helped to assimilate to prescribed norms of participation in schooling practices. Theories of inclusion essentially ask 'How can we make the normal accessible?' or 'how can we include all students into what is already happening here?' Interestingly and relatedly, the inverse of the assertion that it is normal for a person to be different is an interrogation into the assertion that it is normalcy that is natural. As Carlyn Mueller posits in her article in this edition, the reality of what it means to be different is constructed by those who are, for the purposes of the designation process, 'normal.' These people, the deciders of 'normal,' then, lack the consciousness and epistemic orientation born of the difference that Carlyn Mueller characterizes in her interviews with students with subjective disabilities in schools. She adeptly describes the consciousness that develops from the label of being different, and challenges that the meaning of what it is to be 'different' is owned by those who live it. From this consciousness springs material knowledge, and only inquiry from this knowledge can hold both a magnifying glass and a mirror to any society that assumes an ontological orientation rooted in ableism. Accordingly, Thorius has 
assembled a set of papers in this special issue that may be used to confront so-called inclusive approaches and challenge a shift away from assimilation toward deeper reconceptualization of how schooling practices for students across a broad spectrum of difference challenges the notion of a normalized existence in the first place.

Correspondingly, David Hernandez-Saca and Mercedes Cannon introduce an epistemology born of existing at the intersections of race and dis/ability through an incorporation of spirituality. Hernandez-Saca and Cannon challenge the medical model of disability and material body politics by implicating affective and spiritual development into their autoethnographical inquiry. They examine the effects of flawed foundations of special education, noting that subjective labeling practices result in the disproportionate representation of historically marginalized youth in special education, the continued erosion of students' rights, and the hegemonic reproduction of Whiteness in schools. Through an analysis of their own experiences regarding how their labels were formed, they describe what their respective labels at raced, sexed, and other intersections have meant materially and emotionally in this world, and how the assumed validity of a spiritual intuitiveness about their own experiences challenges dominant interpretations of dis/ability hyperfocused on the physical and ideological.

Django Paris asserts that any inquiry into difference, itself, and racial difference specifically, relies on the White gaze, which has long colonized space while erasing the heritages, languages, entire peoples, and epistemologies of those who first inhabited it. Relatedly, educational research has played an integral and essential role in the 'invention' of a normal person, rooted in statistical interpretations that develop and establish the traits of normality (Gallagher, 2010, p. 35). Paris challenges the deficiency-based naming of objects of inquiry in educational research, demonstrating how, through social media platforms such as Twitter, Black and Native people 
have 'push(ed) to exist and name beyond the White settler, cis-hetero-patriarchal gaze....' I extend this challenge to include online forums as a place for those people who exist at the intersections of dis/ability and race to take back their names, to mobilize through ideas and representations that de-center normative assumptions of engagement rooted in a White, settler, cis-hetero-patriarchal, ableist gaze.

Relatedly, by implicating the White gaze, we can move to indict the notions of smartness and goodness (Leonardo \& Broderick, 2011) as measured against a normative standard rooted in Whiteness and statistical normativity, as well as evaluated through a gaze that assumes value in difference only when positioned as relative to specific notions of competence and behavior (Leonardo \& Broderick, 2011), and capitalistic productivity. As Federico Waitoller, Nicole Nguyen, and Gia Super assert in their article, the difference in schools is made corporeal through race and dis/ability, and exists in a politicized educational environment that relies on Taylorist output production by students. The network of corporate charter schools in Chicago, propagated by neoliberal policy made possible through market-friendly legislation, rests on the premise that specific ideations and performances of goodness and smartness (Leonardo \& Broderick, 2011) can be achieved through the implementation of institutional control over students' bodies. When this does not occur, the linguistic deployment of dis/ability for failure to perform or failure to adhere to the 'rigor' of the school's instructional and behavioral control tactics segregates those students with dis/abilities, and especially students of color with dis/abilities.

Interestingly, the linguistic deployment of dis/ability as an exclusionary mechanism is not necessarily as blatant as simply asserting 'Your child is dis/abled, s/he cannot attend this school,' but is often instead deployed under what Kathleen King Thorius names as a 'cloak of benevolence.' Thorius articulates what has long run as an undercurrent of inclusionist schooling 
practices: that special education and its agents serve to remediate, fix, and eliminate difference under the guise of helping children with dis/abilities participate in general education practices (Dudley-Marling \& Gurn, 2010). When pushing students out of charter schools in Chicago, Waitoller, Nguyen, and Super quote school leaders as framing the dis/ability of the student as incompatible with the school's services, suggesting that the student find a school that may better suit their needs. Such tactics connect with Thorius's premise in that they (1) hide under this cloak of benevolence, position the student in need of helping, and special education services and educators as the helpers, and (2) rely on a colonialist interpretation of disability as an inability to act in prescribed notions of abledness relative to both behavior and competence, without acknowledging that behavior and competence in a free market-era of education depend on economic output principles that fail to acknowledge or account for the relational nature of human interaction, development, and ability. Ultimately, as it pertains to schooling, the challenge is to disrupt ecologies (Annamma \& Morrison, 2018) that depend on interpretations of difference as cases for remediation. Here, Thorius draws out the interpersonal sense-making of racist and ableist methods of education and the educator's role in this upholding, as well as means for its interruption, linking individual sense-making to systemic policy and practices through the insertion of a mediating artifact. Relatedly, Padilla and Tan also deploy a cultural tool to push the necessitation of developing more inclusive spaces beyond inclusionism toward examining how disability is constructed dialogically through policy development and classroom implementation, and what it means to reconceptualize through language the notion of who 'can' and who 'cannot' participate in mathematics education. Ultimately, Padilla and Tan challenge the notion that some intellectual endeavors are only meant for some, at the exclusion of those deemed unfit or ill- 
equipped to participate. The following question to these studies may be whether we can change thought through language, and shift perceptions through mediated engagement.

Seena Skelton drives the intimacy of technical assistance and systems level change through interpersonal meaning-making by situating her knowledge and ontological orientation toward the realities of inclusive education, and what it means to interact with those working in public schools, as a Black woman with a disability providing technical assistance to school leaders across as 13-state region. Skelton centers her own epistemology, experience, and meaning for her work, rooting it in her experience as a Black, female student with a disability receiving services through the public schools, as well as through her position as a school psychologist assessing and making decisions about students, and her experience as the director of a technical assistance center. She engages her own reflexivity to ask how her embodiment of the intersections of multiple minoritized identities can serve to activate tensions in providing technical assistance. Importantly, her inquiry focuses on her own self-reflexivity, and how she leverages it, rather than its impact and effect on those who do not and could not possess the same epistemological understandings and ontological approaches to developing schools toward a more holistic and comprehensive understanding of what it means to be inclusive.

How do we reconfigure ecologies to account for the complex inter-relational and spatial (Gabel, Cohen, Kotel, \& Pearson, 2013) making of difference, while challenging the colonization of disabled epistemologies through racist and ableist prescriptions of segregation for the purpose of assimilation or remediation? This conceptualization, away from competition-reliant, capitalist notions of what it means to 'can' and what it means to 'cannot' implicates the consideration that disability, and difference more broadly, is relational. What it means to be unable does not exist absent an able, and what it means to be abnormal (different) does not exist without an 
assumption of normal, and these designations shift with time, space, and actors. Disabled and disability studies scholars have long challenged that these distinctions have relied on medical models of disability, and have been taking up by educational research, specifically, to craft and a normal person as a mechanism of measurement (Dudley-Marling \& Gurn, 2010; Gallagher, 2010). Disabled and disability studies scholars and activists have challenged and are challenging the bio- and necro-politics of disability subjectivity through scholarship, art, activism, and online engagement (e.g. Acevedo, 2015; Bell, 2017; Gorman, 2016; Goodley, 2001; Linton, 1998;

Shakespeare, 2017). As this edition articulates, the difference takes many forms, is intersectional, and is often characterized and codified by and through educational research. Acknowledging that difference is socially constructed poses challenges to the ablenationalism (Snyder \& Mitchell, 2010) that undergirds not only complex systems of schooling, but the educational research on which these systems rest.

\section{Disclosure statement}

No potential conflict of interest was reported by the author. 


\section{References}

Acevedo, S. M. (2015). Exploring disability identity and disability rights through narratives: Find a voice of their own. Disability \& Society, 30, 1127-1129.

doi: $10.1080 / 09687599.2015 .1037557$

Annamma, S., \& Morrison, D. (2018). DisCrit classroom ecology: Using praxis to dismantle dysfunctional education ecologies. Teaching and Teacher Education, 73, 70-80.

doi:10.1016/j.tate.2018.03.008

Bell, C. (2017). Is disability studies actually white disability studies? In. L. Davis (Ed.), Disability Studies Reader (5th ed.) (pp. 406-415). New York, NY: Routledge.

Dudley-Marling, C., \& Gurn, A. (2010). The myth of the normal curve. New York: Peter Lang Publishing.

Gallagher, D. (2010). Educational researchers and the making of normal people. In C. DudleyMarling \& A. Gurn (Eds.) The myth of the normal curve (pp. 25-38). New York: Peter Lang Publishing.

Gabel, S. L., Cohen, C. J., Kotel, K., \& Pearson, H. (2013). Intellectual disability and space: Critical narratives of exclusion. Intellectual and Developmental Disabilities, 51, 74-80. doi:10.1352/1934-9556-51.01.074

Goodley, D. (2001). 'Learning difficulties', the social model of disability and impairment: Challenging epistemologies. Disability \& Society, 16, 207-231. doi:10.1080/09687590120035816 
Gorman, R. (2016). Disablement in and for itself: Toward a 'global' idea of disability. Somatechnics, 6, 249-261. doi:10.3366/soma.2016.0194

Kauffman, J. M., Lloyd, J. W., Baker, J., \& Reidel, T. M. (1995). Inclusion of all students with emotional or behavioral disorders? Let's think again. Phi Delta Kappan, 76, 542-547.

Kauffman, J. M., \& Badar, J. (2013). How we might make special education for students with emotional or behavioral disorders less stigmatizing. Behavioral Disorders, 39, 16-27. doi:10.1177/019874291303900103

Kauffman, J. M., \& Landrum, T. J. (2018). Characteristics of emotional and behavioral disorders of children and youth. New York, NY: Pearson.

Leonardo, Z. \& Broderick, A. (2011). Smartness as property: A critical exploration of intersections between whiteness and disability studies. Teachers College Record, 113(10), 22062232.

Linton, S. (1998). Claiming disability: Knowledge and identity. New York, NY: New York University Press.

Shakespeare, T. (2017). The social model of disability. In L. Davis (Ed.), Disability Studies Reader (5th ed.) (pp. 195-203). New York, NY: Routledge.

Snyder, S. L., \& Mitchell, D. T. (2010). Ablenationalism and the geo-politics of disability. Journal of Literacy \& Cultural Disability Studies, 4, 113-124. doi:10.3828/jlcds.2010.10 